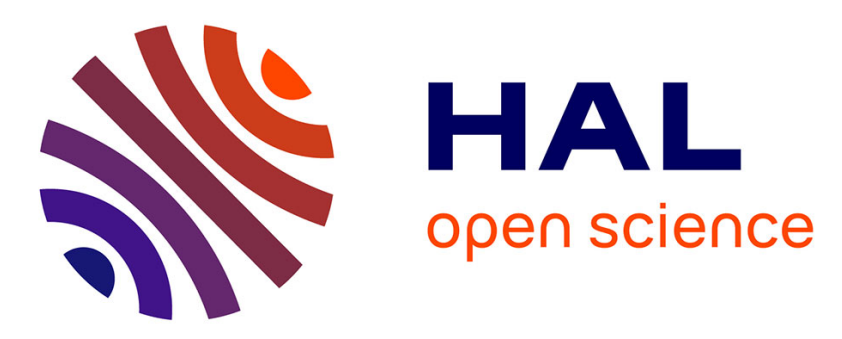

\title{
Characterization of zeolitic intraframework molybdenum sites
}

Gabriella Skara, Rafal Baran, Thomas Onfroy, Frank de Proft, Stanislaw Dzwigaj, Frederik Tielens

\section{To cite this version:}

Gabriella Skara, Rafal Baran, Thomas Onfroy, Frank de Proft, Stanislaw Dzwigaj, et al.. Characterization of zeolitic intraframework molybdenum sites. Microporous and Mesoporous Materials, 2016, 225, pp.355-364. 10.1016/j.micromeso.2015.11.062 . hal-01265851

\section{HAL Id: hal-01265851 https: / hal.sorbonne-universite.fr/hal-01265851}

Submitted on 1 Feb 2016

HAL is a multi-disciplinary open access archive for the deposit and dissemination of scientific research documents, whether they are published or not. The documents may come from teaching and research institutions in France or abroad, or from public or private research centers.
L'archive ouverte pluridisciplinaire HAL, est destinée au dépôt et à la diffusion de documents scientifiques de niveau recherche, publiés ou non, émanant des établissements d'enseignement et de recherche français ou étrangers, des laboratoires publics ou privés. 


\title{
Characterization of Zeolitic Intraframework
}

\author{
Molybdenum Sites
}

Gabriella Skara ${ }^{1}$, Rafal Baran ${ }^{2,3}$, Thomas Onfroy ${ }^{2}$, Frank De Proft $^{1}$, Stanislaw Dzwigaj 2,*,

Frederik Tielens ${ }^{4, *}$

${ }^{1}$ Eenheid Algemene Chemie (ALGC), Member of the QCMM VUB-UGent Alliance Research Group, Vrije Universiteit Brussel, Pleinlaan 2, Brussels, Belgium

${ }^{2}$ Sorbonne Université, UPMC Univ Paris 06, CNRS, UMR 7197, Laboratoire de Réactivité de

Surface, Case 178, Site d'Ivry-Le Raphaël, 3 rue Galilée, 94200 Ivry sur Seine, France

${ }^{3}$ AGH University of Science and Technology, Faculty of Energy and Fuels, Department of Fuel Technology, al. A. Mickiewicza 30, 30-059 Krakow, Poland

${ }^{4}$ Sorbonne Université, UPMC Univ Paris 06, CNRS, UMR 7574, Laboratoire Chimie de la Matière Condensée, Collège de France, 11 place Marcelin Berthelot, 75231 Paris Cedex 05, France

KEYWORDS: Sodalite, Molybdenum, BEA, RAMAN, DFT. 


\section{ABSTRACT}

An integrated experimental and computational study was carried out on molybdenum loaded BEA zeolite in order to scrutinize the most stable state of the molybdenum site at various oxidation and hydration states. After a two-step post-synthetic process, the incorporation of Mo ions into the vacant $\mathrm{T}$-atom sites of the SiBEA framework zeolite as mononuclear $\mathrm{Mo}^{\mathrm{VI}}$ centers has been evidenced by combined use of XRD, FTIR and diffuse reflectance UV-vis spectroscopy. The consumption of $\mathrm{OH}$ groups upon Mo loading has been monitored by FTIR and adsorbed pyridine is used as probe molecules for characterization of Brønsted and Lewis acidity in SiBEA and Mo3.0SiBEA. Periodic DFT calculations in sodalite (SOD) framework indicate a trigonalbipyramidal conformer at the $\mathrm{Mo}^{\mathrm{VI}}$ site with molybdenum being incorporated into the zeolite framework by four $\mathrm{SiO}-$ bonds and a $\mathrm{Mo}=\mathrm{O}$ functionality under anhydrous conditions. Water splitting formally to $\mathrm{O}^{2-}$ and $2 \mathrm{H}^{+}$is computed to be feasible in SOD cage, whereas it is strongly favored in MoBEA framework at the T1 position. Depending on the hydration state, it is shown that the Mo sites formed can exhibit two $\mathrm{Mo}=\mathrm{O}$ functionalities in a trigonal-bipyramidal and a pseudo-octahedral arrangement. 


\section{Introduction}

Transition metal modified or substituted oxide materials have found many applications in catalysis. Zeolites, a typical group of materials used as support for heterogeneous catalysts are used for decades in industrial applications. The continuous search to improve or discover new catalyst has led to the chemical modification of the oxide support or zeolite in particular at atomic level $^{1} .^{2}$

In earlier work Dzwigaj et al. ${ }^{3-5}$ have applied a two-step post-synthesis method to favor the incorporation of group VI metal, chromium, into the framework of the BEA zeolite and to obtain mononuclear chromium species. The transition metal intra framework site was characterized using a series of experimental techniques, followed by quantum chemical calculations by the Tielens group $^{6}$. A logic continuation of this study is the introduction of the other group VI elements, Mo, and $\mathrm{W}$ into the zeolite structure, in the same spirit as for the group $\mathrm{V}$ transition metals performed earlier: $\mathrm{V}^{7-11}, \mathrm{Nb}^{12}, \mathrm{Ta}^{13}$, and $\mathrm{Cr}^{14}$.

Molybdenum species grafted on silica have attracted considerable attention because of their relevance to a variety of catalytic reactions, including the selective oxidations of alkanes ${ }^{15,16}$, alkenes $^{17}$, and alcohols ${ }^{18,19}$. Many research groups have reported methods of characterization and synthesis, which is supposed to generate specific surface molybdenum oxide species. It is well known that framework transition metal ions are considered to be active in selective oxidation reactions ${ }^{20-23}$. Nevertheless, the structure, stability and reactivity of Mo oxide functionalities encapsulated in zeolites are much less studied, especially as isolated mononuclear species.

To our knowledge no combined theoretical/experimental characterization studies are available on molybdenum oxide species inserted into zeolite frameworks. The most related material known to pure silica molybdenum zeolites is molybdenum oxide supported on silica surface. This material 
characterized by SiO-Mo linkages and has been thoroughly investigated, and molecular models have been studied theoretically ${ }^{24}$.

The still growing computational power enables us to study models with increasing complexity and reliability. Until now, ab initio quantum chemical calculations have been performed on cluster models involving only dozen of atoms ${ }^{25-27}$. The present work follows the same spirit as those performed on the group $\mathrm{V}$ elements ${ }^{28-30}$, and in particular Si substituted by $\mathrm{Cr}$, characterized experimentally on BEA zeolite and theoretically using periodic DFT ${ }^{6}$.

Different framework site models are proposed after a systematic theoretical study. The sites are characterized by structural parameters, vibrational frequencies, and (de)protonation energies. The results are in good agreement with the experimental findings.

\section{Experimental Details}

\section{Material preparation}

A tetraethylammonium BEA (TEABEA) zeolite with a $\mathrm{Si} / \mathrm{Al}$ atomic ratio of 17 provided by RIPP (China) was dealuminated by a treatment with nitric acid solution $\left(\mathrm{c}=13 \mathrm{~mol} \mathrm{~L}^{-1}\right)$ at $353 \mathrm{~K}$ for $4 \mathrm{~h}$, to obtain $\mathrm{SiBEA}$ with atomic $\mathrm{Si} / \mathrm{Al}$ ratio $>1300$ and then washed several times with distilled water and dried at $368 \mathrm{~K}$ overnight.

SiBEA zeolite and molybdenum(II) acetate with a desired amount of Mo (3 Mo wt. \% in Mocontaining SiBEA sample) were ground and mixed in agate mortar for 15 minutes. The obtained mixture was transferred to glass reactor and heated in flowing argon of $150 \mathrm{~mL} \mathrm{~min}^{-1}$ up to $773 \mathrm{~K}$ with heating rate of $2 \mathrm{~K} \mathrm{~min}^{-1}$ and left in this temperature for $12 \mathrm{~h}$. After that, the gas flow was changed from argon to oxygen and the solid was calcined at $773 \mathrm{~K}$ for $3 \mathrm{~h}$. As obtained, Mocontaining SiBEA was labeled Mo3.0SiBEA. 


\section{Material characterization}

Power X-ray diffractograms (XRD) of the prepared samples were recorded at room temperature on a Bruker D8 Advance diffractometer using the $\mathrm{CuK}_{\mathrm{a}}$ radiation $(\lambda=154.05 \mathrm{pm})$.

Analysis of the acidic properties of samples was performed by adsorption of pyridine (Py) followed by transmission FT infrared spectroscopy. Before analysis, the samples were pressed at $\sim 1$ ton $\mathrm{cm}^{-2}$ into thin wafers of ca. $10 \mathrm{mg} \mathrm{cm}^{-2}$ and placed inside the IR cell.

Before Py adsorption/desorption experiments, the wafers were activated by calcination in static conditions at $723 \mathrm{~K}$ for $3 \mathrm{~h}$ in $\mathrm{O}_{2}\left(1.610^{4} \mathrm{~Pa}\right)$ and then outgassed under secondary vacuum at 573 $\mathrm{K}\left(10^{-3} \mathrm{~Pa}\right)$ for $1 \mathrm{~h}$. These wafers were contacted at room temperature with gaseous $\mathrm{Py}(133 \mathrm{~Pa})$ via a separate cell containing liquid Py. The spectra were then recorded following desorption from 423 and $573 \mathrm{~K}$ with a Bruker Vector 22 spectrometer (resolution $2 \mathrm{~cm}^{-1}, 128$ scans). The reported difference spectra were obtained after subtraction of the spectrum recorded before Py adsorption.

Diffuse reflectance (DR) UV-vis spectra of Mo3.0SiBEA were recorded at ambient atmosphere on a Cary 5000 Varian spectrometer equipped with a double integrator with polytetrafluoroethylene.

\section{Computational Details}

Periodic density functional theory (DFT) calculations were performed using ab initio planewave pseudopotentials implemented in the Vienna Ab Initio Simulation Package ${ }^{31,32}$. The gradient-corrected revised Perdew-Burke-Ernzerhof (PBE) exchange-correlation functional ${ }^{33,}, 34$ was chosen to carry out all calculations. The valence electrons and their interactions with the ionic cores were described with the projector augmented-wave (PAW) method ${ }^{35,36}$ and for valence electrons a plane wave basis set was applied. 
A $(3 \times 3 \times 3)$ k-point grid is used in the Brillouin-zone sums, and the partial occupancies are set for each wave function using the tetrahedron method with Blöchl corrections ${ }^{37}$. The convergence was reached when the total energy difference between the self-consistent field loops was less than $10^{-4} \mathrm{eV}$. To calculate the Hessian matrix each ion was displaced in all three Cartesian directions.

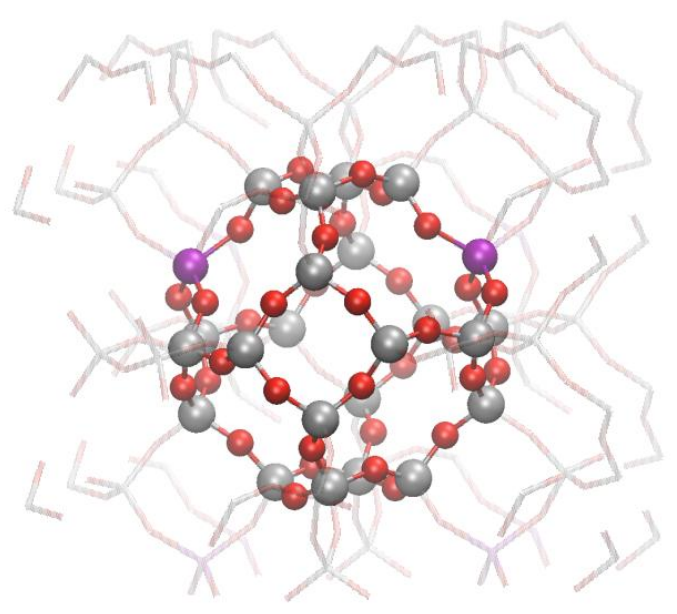

Figure 1. Structure of model sodalite (SOD) cage in a supercell. (Mo substituted position is in purple)

The sodalite structure (SOD, Figure 1), commonly referred as the $\beta$-cage was used to perform a systematic study using periodic calculations. The use of the SOD cage as a model for a zeolite and in particular for BEA zeolite has been compared and justified in our previous study ${ }^{11}$. The unit cell has a regular network of tetrahedral sites (equal T-sites) and contains 36 atoms $\left(\mathrm{Si}_{12} \mathrm{O}_{24}\right)$. The use of such a small periodically repeated model makes the computationally very demanding calculations attainable. We also calculated, however, the most stable structures in BEA zeolite, to investigate the effect of the unit cell flexibility on the Mo insertion. The BEA unit cell contains 192 atoms $\left(\mathrm{Si}_{64} \mathrm{O}_{128}\right)$, and has 9 different T-sites. We verified our calculations in the $\beta$-cage in 
three different T-sites, namely $\mathrm{T} 1, \mathrm{~T} 2$, and $\mathrm{T}$, which were previously shown for $\mathrm{V}, \mathrm{Nb}$, Ta inserted BEA zeolites to exhibit very different affinity to host metal ions ${ }^{11}$.

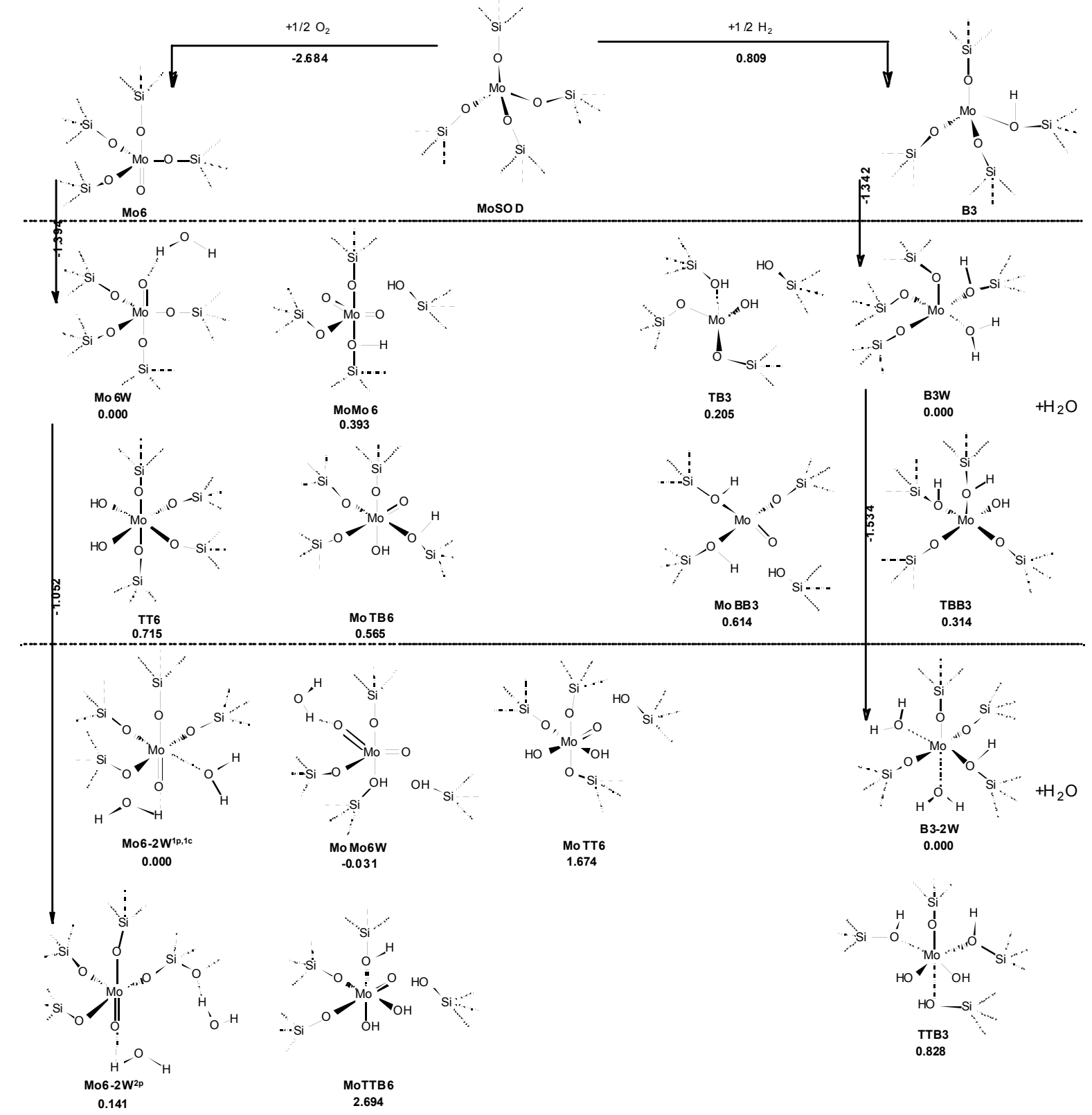

Figure 2. Investigated Mo model sites in sodalite framework as the function of the Mo oxidation state and degree of hydration. Relative energies are given in $\mathrm{eV}$ for each corresponding series, and reaction energies $\left(\Delta \mathrm{E}_{\mathrm{r}}\right)$ in $\mathrm{eV}$ on the arrows. 
Several configurations were systematically investigated to study the environment of the Mo site as the function of its oxidation state and its degree of hydration (Figure 2). This study is a complementary work to our previous work on chromium-substituted zeolite ${ }^{6}$. We started from a hypothetical structure in which one silicon atom of the pure $\mathrm{SiO}_{2}$ framework is isomorphously substituted by one molybdenum atom, where the oxidation state of the transition metal is +4 (MoSOD). As a next step the metal center was reduced and oxidized by molecular hydrogen $\left(\mathrm{H}_{2}\right.$, right in Figure 2) and oxygen $\left(\mathrm{O}_{2}\right.$, left in Figure 2), respectively to form the parent $\mathrm{Mo}^{\mathrm{III}}(\mathbf{B 3})$ and $\mathrm{Mo}^{\mathrm{VI}}$ (Mo6) sites. For both species, we added up to two water molecules (dissociated or not) and considered $\mathrm{Mo}=\mathrm{O}$ and $\mathrm{Mo}-\mathrm{OH}$ groups in the structures as summarized in Figure 2. In order to distinguish the different functional groups formed in the site and to be consistent with earlier studies, we use our previously introduced nomenclature ${ }^{10-12}$ system being the following: B (Bridging hydroxyl), T (Terminal $\mathrm{OH}$ group), Mo (Mo=O, molybdenyl group), and $\mathrm{nW}$ (n physisorbed or chemisorbed water molecules). The Arabic number next to letter code indicates the oxidation state of the metal. The schematic representations of the different models and their relationship with each other are shown in Figure 2.

\section{Results and discussion}

\section{Experimental investigation}

\section{Incorporation of molybdenum into the framework of SiBEA evidenced by XRD and FTIR}

As Figure 3 indicates, the X-ray diffractograms of SiBEA and Mo3.0SiBEA are similar, suggesting that the incorporation of molybdenum into framework of SiBEA zeolite does not significantly affect the structure of the zeolite. While the determination of the unit cell parameters in BEA zeolite is made difficult because of the coexistence of several polytypes, it is, however, 
possible to obtain information on the contraction/expansion of the framework from the position of the diffraction peak (302) at $2 \theta=22.5-22.7^{\circ}$.

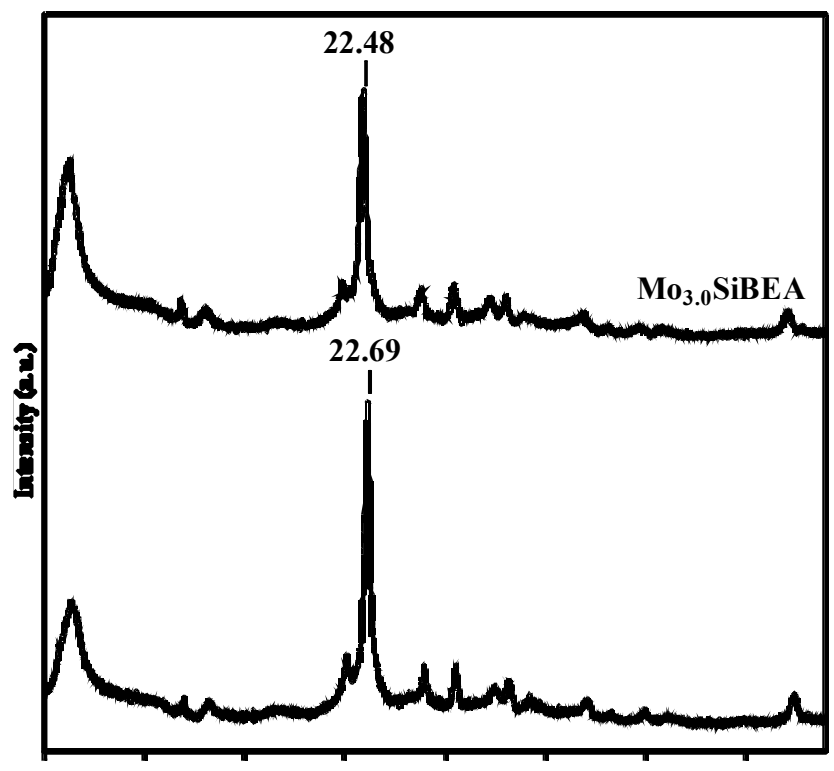

Figure 3. X-ray diffractograms of SiBEA and $\mathrm{Mo}_{3.0} \mathrm{SiBEA}$ recorded at room temperature and ambient atmosphere.

Upon introduction of Mo into SiBEA the $\mathrm{d}_{302}$ spacing, related to the narrow main diffraction peak near $22.7^{\circ}$, increases from $3.920 \AA$ (SiBEA) (with $2 \theta$ of $22.69^{\circ}$ ) to $3.950 \AA\left(\mathrm{Mo}_{3.0} \mathrm{SiBEA}\right)$ (with $2 \theta$ of $22.48^{\circ}$ ) (Figure 3). This increase can be taken as an evidence of framework expansion of the BEA structure and suggests incorporation of molybdenum atoms into the vacant-T-atom sites of the framework of SiBEA zeolite, in line with earlier reports for $\mathrm{Cr}_{\mathrm{x}} \mathrm{SiBEA}^{6}$, VSiBEA zeolites $^{38}$.

\section{Formation of Isolated Mo ${ }^{\mathrm{VI}}$ Species in SiBEA evidenced by DR UV-vis}




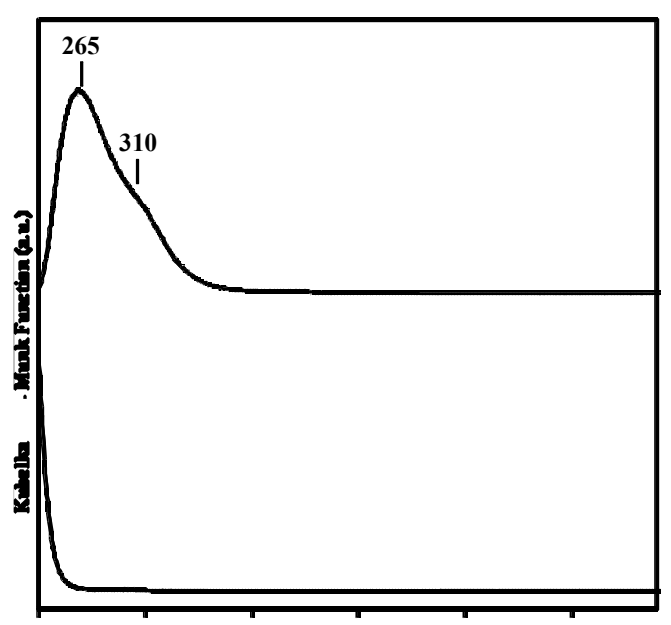

Figure 4. DR UV-vis spectra of $\mathrm{SiBEA}$ and $\mathrm{Mo}_{3.0} \mathrm{SiBEA}$ recorded at ambient atmosphere.

Figure 4 shows the diffuse reflectance UV-vis spectra of SiBEA and Mo3.0SiBEA. For Mo3.0SiBEA only two absorption bands at 265 and $310 \mathrm{~nm}$ appear. These new absorption bands observed can be assigned to ligand to metal low-energy charge transfer (LMCT) transitions ${ }^{39,40}$ involving oxygens in bridging $(\mathrm{Mo}-\mathrm{O}-\mathrm{Si})$ and terminal $(\mathrm{Mo}=\mathrm{O})$ positions, which is in line with Mo-containing materials and earlier works on $\mathrm{V}^{\mathrm{V}}$ - and $\mathrm{Cr}^{\mathrm{VI}}$-containing zeolites ${ }^{3,}$ 41-44. Conventionally, absorption bands between 250 and $280 \mathrm{~nm}$ are assigned to a tetrahedral, whereas bands from 300 to $330 \mathrm{~nm}$ to an octahedral geometry of isolated molybdenum oxide centers ${ }^{45,46}$. The absence of $\mathrm{d}$-d transition within the range of $600-800 \mathrm{~nm}$ indicates that practically all molybdenum centers are oxidized to $\mathrm{Mo}^{\mathrm{VI}}$ and no reduced $\mathrm{Mo}^{\mathrm{III}}$ or $\mathrm{Mo}^{\mathrm{IV}}$ forms are present. 


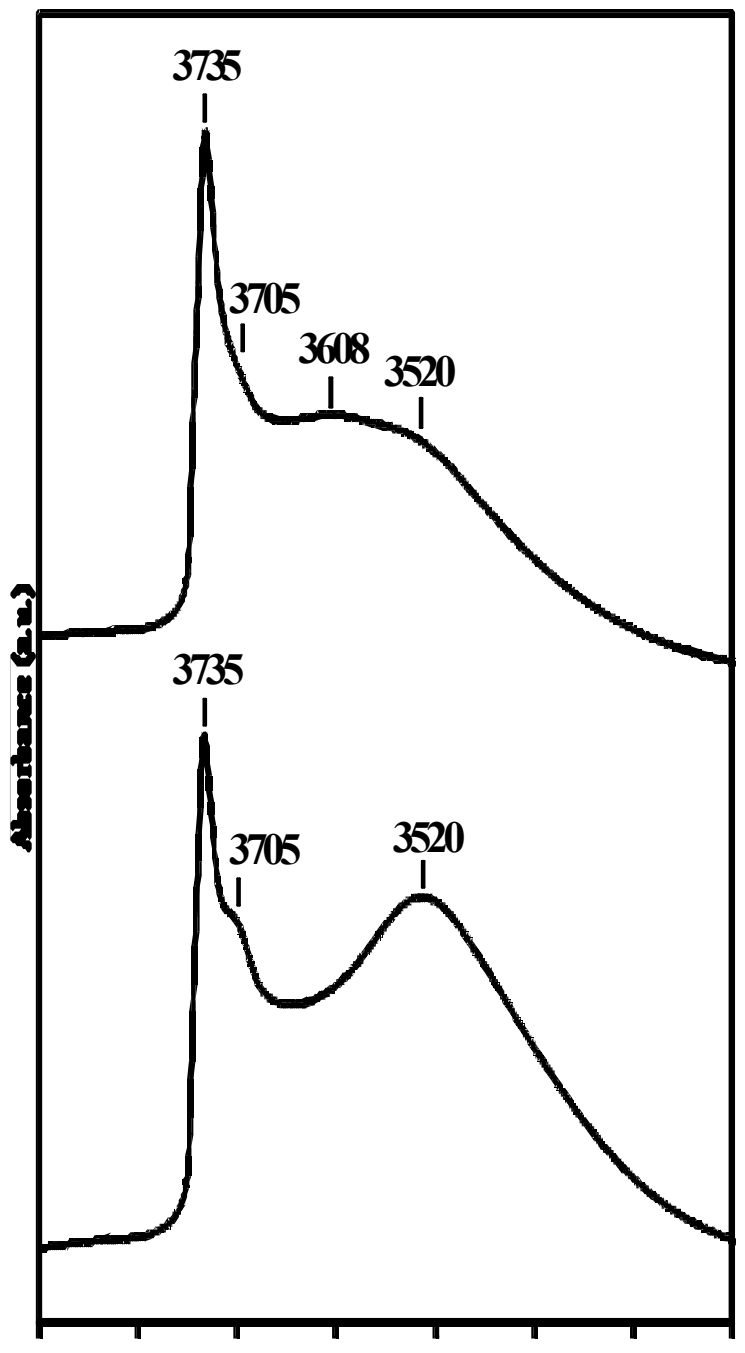

Figure 5. FTIR spectra recorded at room temperature of SiBEA and Mo3.0SiBEA calcined at 773 $\mathrm{K}$ for $2 \mathrm{~h}$ in flowing $2.5 \% \mathrm{O}_{2} / \operatorname{Ar}\left(50 \mathrm{~mL} \mathrm{~min}^{-1}\right)$ and then outgassed at $573 \mathrm{~K}\left(10^{-3} \mathrm{~Pa}\right)$ for $1 \mathrm{~h}$.

\section{FTIR spectroscopy.}

The IR bands at 3735 and 3705 (Figure 5) are attributed to isolated internal SiO-H groups of SiBEA and the broad band of $3520 \mathrm{~cm}^{-1}$ shows the presence of vacant $\mathrm{T}$-atom sites associated with SiO-H groups, as previously shown ${ }^{4,41,47}$. The incorporation of molybdenum into SiBEA leads to the decreasing of the intensity of the IR bands at 3735,3705 and $3520 \mathrm{~cm}^{-1}$ of terminal internal 
and hydrogen bonded SiO-H groups (Figure 5), respectively, and suggest that those silanol groups react with the Mo precursor.

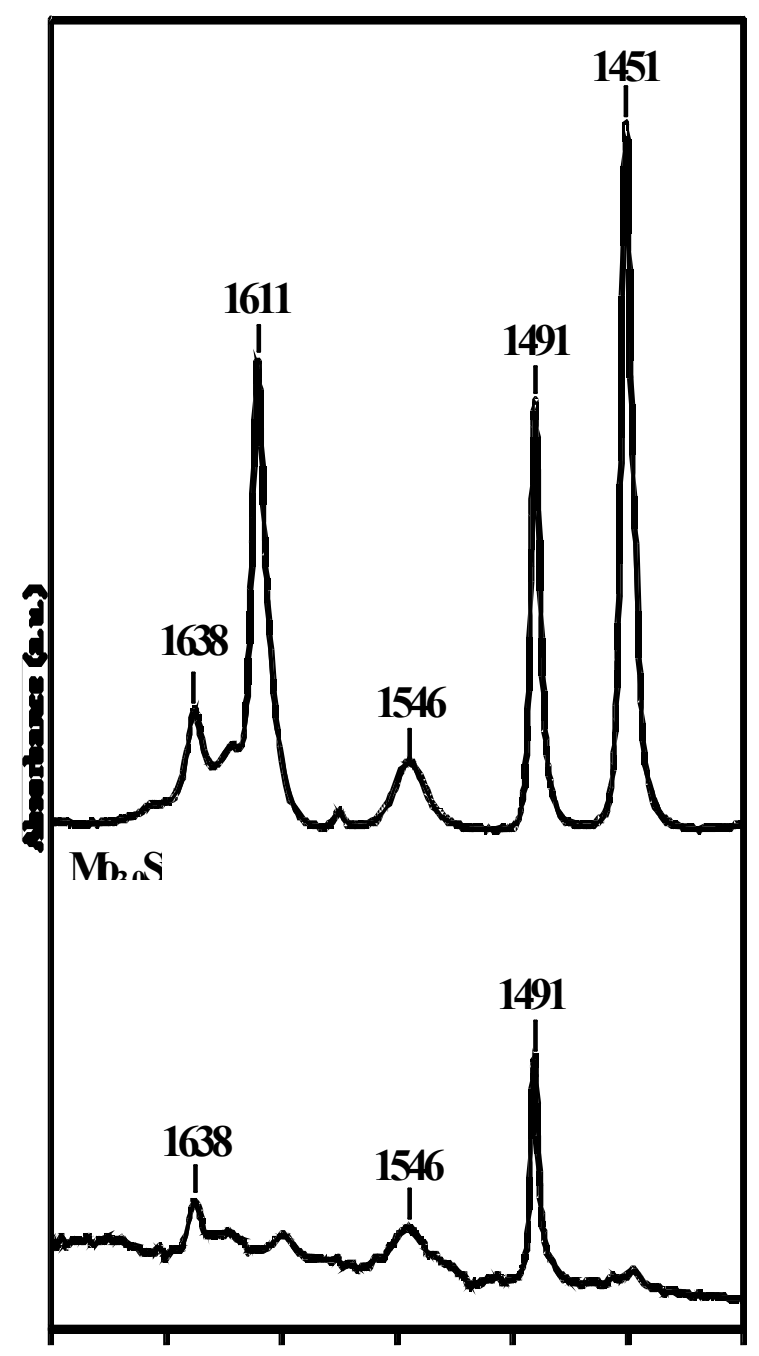

Figure 6. FTIR difference spectra recorded at room temperature of SiBEA and Mo ${ }_{3.0} \mathrm{SiBEA}$ (calcined at $673 \mathrm{~K}$ for $1 \mathrm{~h}$ in $\mathrm{O}_{2}\left(2 \cdot 10^{4} \mathrm{~Pa}\right)$ and then outgassed at $673 \mathrm{~K}\left(10^{-3} \mathrm{~Pa}\right)$ for $\left.1 \mathrm{~h}\right)$ after adsorption of pyridine for $1 \mathrm{~h}$ at $423 \mathrm{~K}$ and then desorption at $423 \mathrm{~K}$ for $1 \mathrm{~h}$.

Figure 6 shows the FTIR difference spectra recorded at ambient temperature of SiBEA and $\mathrm{Mo}_{3.0} \mathrm{SiBEA}$, after calcination at $673 \mathrm{~K}$ for $1 \mathrm{~h}$ under $\mathrm{O}_{2}$ and then outgassed at $673 \mathrm{~K}\left(10^{-3} \mathrm{~Pa}\right)$ for 
$1 \mathrm{~h}$ after adsorption of pyridine recorded at $423 \mathrm{~K}$ temperature and followed desorportion at 423 K.

For SiBEA very small bands at 1638,1546 and $1491 \mathrm{~cm}^{-1}$ are observed indicating the presence of only very low amounts of Brønsted and Lewis acidic sites (Figure 6, Table 1 in line with earlier reports on SiBEA and VSiBEA ${ }^{42,48}$. The bands typical of pyridinium cations ${ }^{3,49-51}$ are observed at 1638 and $1546 \mathrm{~cm}^{-1}$ indicating the presence of Brønsted acidic sites and suggesting that $=\mathrm{Mo}-$ $\mathrm{O}(\mathrm{H})-\mathrm{Si}=$ acidic sites (see also section acid base properties) are formed upon outgassing of Mo3.0SiBEA, as were suggested earlier also for $\mathrm{Cr}_{\mathrm{x}} \mathrm{SiBEA}^{6}$ and $\mathrm{VSiBEA}^{8,10}$. The other bands observed at 1611 and $1451 \mathrm{~cm}^{-1}$ correspond to pyridine interacting with strong Lewis acidic sites related to $\mathrm{Mo}^{\mathrm{VI}}$ species (See Table 1), confirming the formation of bridging $\mathrm{Mo}^{\mathrm{VI}}-\mathrm{O}(\mathrm{H})-\mathrm{Si}$ groups in Mo3.0SiBEA, which is in line with earlier data for $\mathrm{CrSiBEA}^{3}$ and $\mathrm{VSiBEA}^{42,48}$.

Table 1. Evolution of Brønsted and Lewis acidic centers concentration in SiBEA and Mo3.0SiBEA samples. (Values in $\mu \mathrm{mol} \mathrm{g} \mathrm{g}^{-1}$ )

\begin{tabular}{ccc}
\hline Samples & $\begin{array}{c}\text { Brønsted acidic } \\
\text { centers }\end{array}$ & $\begin{array}{c}\text { Lewis acidic } \\
\text { centers }\end{array}$ \\
\hline SiBEA & 8 & 3 \\
Mo3.0SiBEA & 13 & 53 \\
\hline
\end{tabular}

\subsection{Theoretical investigation}

\section{Geometry and energetics of the Mo-zeolite framework sites}

The geometrical parameters of the substituted framework sites are obtained after full optimization; ion positions, cell volume and cell shape were allowed to relax. The spin state of the different $\mathrm{Mo}^{\mathrm{III}}, \mathrm{Mo}^{\mathrm{IV}}$, $\mathrm{Mo}^{\mathrm{VI}}$ models has been investigated and respected. For $\mathrm{Mo}^{\mathrm{III}}$ structures, 
quartet state was always found to be lower in energy, than the doublet state, whereas for $\mathrm{Mo}^{\mathrm{VI}}$, being $\mathrm{d}^{0}$, only the singlet state was considered. The $\mathrm{Mo}^{\mathrm{IV}}$ state, $\mathrm{d}^{2}$, was calculated as triplet. The bond distances and angles of the most stable optimized structures are tabulated in Table 2 and are used to determine the type of the Mo-O bonds in the zeolites.

Table 2. Unit cell volume $\left(\AA^{3}\right)$, reaction energies $(\mathrm{eV})$, coordination number and bond distances $\mathrm{D}(\AA)$ of the different reactive sites.

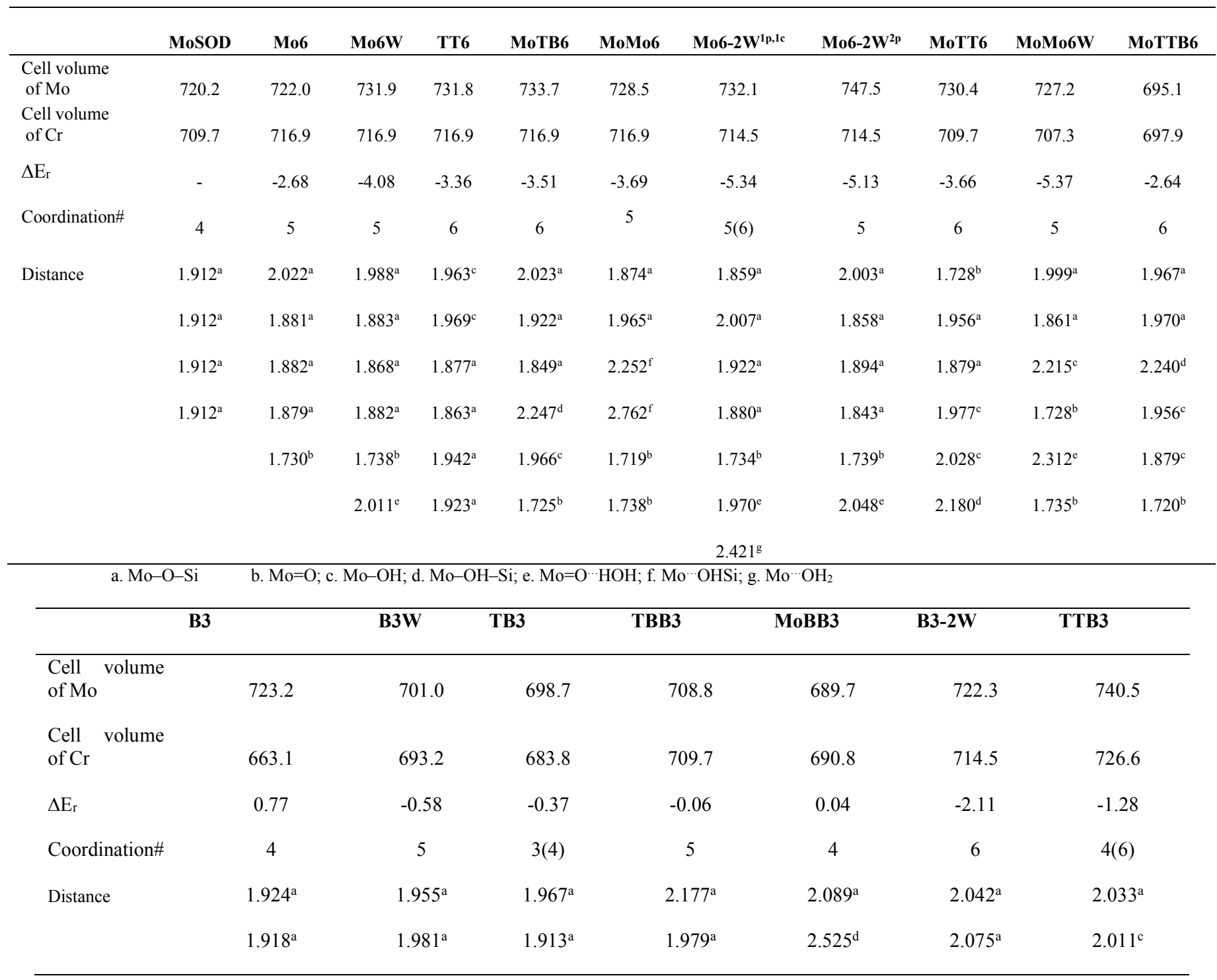




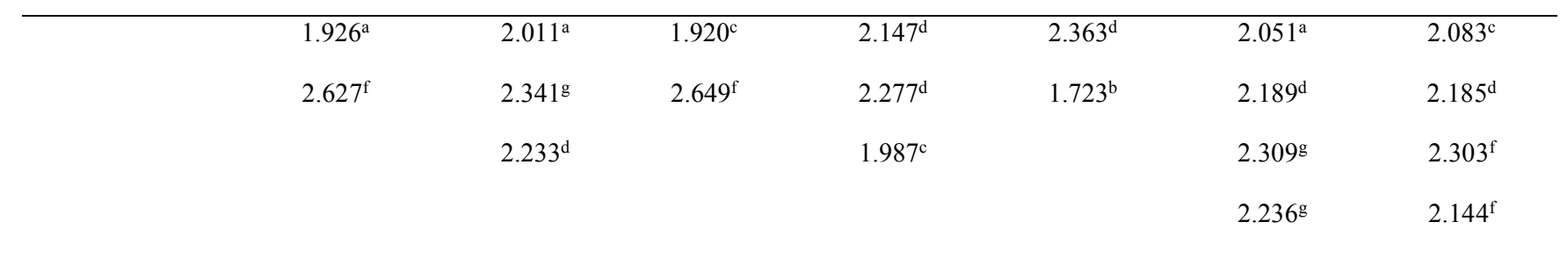

a. $\mathrm{Mo}-\mathrm{O}-\mathrm{Si} \quad$ b. $\mathrm{Mo}=\mathrm{O}$; c. $\mathrm{Mo}-\mathrm{OH}$; d. $\mathrm{Mo}-\mathrm{OH}-\mathrm{Si}$; e. $\mathrm{Mo}=\mathrm{O} \cdots \mathrm{HOH}$; f. Mo $\cdots \mathrm{OHSi}$; g. $\mathrm{Mo}^{\cdots} \mathrm{OH}_{2}$

The $\mathrm{Mo}=\mathrm{O}$ double bonds adopt interatomic distances from 1.72 to $1.74 \AA$, which agrees well with bond lengths observed in tetrahedral $\mathrm{MoO}_{4}{ }^{2-}$, pentacoordinated $\mathrm{Mo}_{3} \mathrm{O}_{12}{ }^{6-}$ and octahedral $\mathrm{MoO}_{6}{ }^{6-}$ type molybdenum oxides ${ }^{24,52}$. The Mo-OSi bonds are characterized by typical lengths of $1.85-2.09 \AA$, while terminal Mo-OH bonds are slightly longer in general varying between 1.86 and $2.08 \AA$. Significantly weaker $\mathrm{Mo} \cdots \mathrm{O}$ attractions are predicted for the interaction of the molybdenum center with neutral ligands, such as $\mathrm{O}(\mathrm{H}) \mathrm{Si}-$ and $\mathrm{H}_{2} \mathrm{O}$. It is in line with the decreasing electron donating ability and decreasing electrostatic attraction of oxygen when going from the formal - 2 charge to neutral form. Interactions characterized by distances between 2.0 and $2.2 \AA$ can be viewed as unconstrained dative bonds in the coordination sphere.

Compared to the $\mathrm{Cr}-\mathrm{O}$ bond lengths, the $\mathrm{Mo}-\mathrm{O}$ bonds further elongate by about $0.10 \AA$ in general in the sodalite cage, which is in line with the increased ion size as going down in the periodic table. The expansion of the coordination sphere results in the increase of the unit cell volume by about $+2.5 \%$ on average compared to the chromium-substituted models. This finding is again in full agreement with the experimentally determined structure expansions, which is indeed slightly more characteristic for Mo incorporation than for Cr incorporation ${ }^{6}$. Note that there are also systems, for example TB3 $\left(698.7 \AA^{3}\right)$, with smaller unit cell than the parent MoSOD structure. As discussed for the CrSOD to $\mathrm{B} 3(\mathrm{Cr})$ case $^{6}$, this behavior can be linked to the shrinkage caused by the evolution of plausible hydrogen networks between well oriented $\mathrm{OH}$ donor and $\mathrm{O}$ acceptor functionalities. 
Concerning the relative energy of the various states, the MoSOD with $\mathrm{Mo}^{\mathrm{IV}}$ oxidation states has been taken as the reference configuration and the relative energies were defined as the reaction energy $\left(\Delta \mathrm{E}_{\mathrm{r}}\right)$ of the following reaction:

$$
\mathrm{MoSOD}+\mathrm{n} \mathrm{O}_{2}+\mathrm{m} \mathrm{H}_{2}+\mathrm{k} \mathrm{H}_{2} \mathrm{O}-->\mathrm{Mo}(\mathrm{X}) \mathrm{SOD}
$$

, where $\mathrm{n}=0$, or $1 / 2, \mathrm{~m}=0$, or $1 / 2$, and $\mathrm{k}=0,1$, or $2, \mathrm{X}$ (oxidation state $)=+3$ or +6

For products $\mathbf{M o 6}(\mathrm{n}=1 / 2, \mathrm{~m}, \mathrm{k}=0)$ and $\mathbf{B 3}(\mathrm{m}=1 / 2, \mathrm{n}, \mathrm{k}=0)$, the reaction energy can give, as first approximation, an idea about the feasibility of oxidation and reduction processes, respectively, starting from $\mathrm{Mo}^{\mathrm{IV}}$ loaded zeolites. The oxidation $(-2.68 \mathrm{eV})$ is highly exothermic revealing a spontaneous process, whereas the reduction is endothermic and needs $0.81 \mathrm{eV}$ to take place. These results might be linked to the exclusively observed $\mathrm{Mo}^{\mathrm{VI}}$ state, unlike $\mathrm{Mo}^{\mathrm{III}}$, in the various experiments. Also, for example, going from Mo6 to Mo6W and Mo6-2W, the relative $\Delta \mathrm{E}_{\mathrm{r}}$ values indicate the energy associated with water adsorption in $\mathrm{Mo}^{\mathrm{VI}}$ containing SOD cage. These values are extracted from the $\Delta \mathrm{E}_{\mathrm{r}}$ values and given in Figure 2 (vertical). The computed values of -1.39 and $-1.05 \mathrm{eV}$ for water adsorption are consistent with previously reported values of $1.66-1.13 \mathrm{eV}$ in high-silica zeolites ${ }^{53}$, indicating energetically favored adsorption processes.

Most importantly, the relative stabilities of isomeric sites, i.e. structures with the same oxidation state and hydration, can be determined by comparing their $\Delta \mathrm{E}_{\mathrm{r}}$ values. Accordingly, four groups of species can be distinguished (Group 1-4). Group 1 with $\mathrm{Mo}^{\mathrm{VI}}$ center and with one equivalent of water contains Mo6W, TT6, MoTB6 and MoMo6, whereas formal addition of a water molecule to the systems (Group 2) results in structures Mo6-2W ${ }^{1 p}, 1 \mathbf{c}$, Mo6-2W ${ }^{2 p}$, MoTT6, MoTTB6 and MoMo6W, all depicted schematically in Figure 2. Similarly, two sets of Mo ${ }^{\mathrm{III}}$ systems can be identified: Group 3 (B3W, TB3, TBB3 and MoBB3) and Group 4 (B3-2W and TTB3) contains one and two added water molecules in the system, respectively. 
The most stable $\mathrm{Mo}^{\mathrm{VI}}$ state after hydration (Group 1) is the simple physisorbed structure, Mo6W, in which the adsorbed water molecule forms a strong hydrogen bond $(\mathrm{d}=2.01 \AA)$ with the molybdenyl $(\mathrm{Mo}=\mathrm{O})$ group (Figure 2). MoMo6 represents the second most stable species lying $0.39 \mathrm{eV}$ higher in energy than Mo6W. In the latter structure the water molecule is formally split into $\mathrm{O}^{-2}$ and $2 \mathrm{H}^{+}$to form the second $\mathrm{Mo}=\mathrm{O}$ functionality and two $\mathrm{Si}-\mathrm{OH}$ termini (Figure 2 and Figure 7). The two other $\mathrm{Mo}^{\mathrm{VI}}$ structures (TT6 and MoTB6) having only one molybdenyl $(\mathrm{Mo}=\mathrm{O})$ group and adopting hexacoordinated octahedral geometry lie significantly higher in energy than the former two structures. Further hydration causes notable change in the relative energies: Mo6$\mathbf{2 W}^{\mathbf{1 p}, \mathbf{1 c}}$ with one metal coordinated water and one physisorbed water molecules and MoMo6W (Figure 7), which represents the above described $\left[(\mathrm{SiO})_{2} \mathrm{MoO}_{2}\right]$ core with one physisorbed water, become the two most stable, practically isoenergetic (within $0.05 \mathrm{eV}$ ) structures. Mo6-2 $\mathbf{W}^{\mathbf{2 p}}$ with two physisorbed water molecules has a relative energy of $0.141 \mathrm{eV}$ respect to Mo6-2W $\mathbf{W}^{\mathbf{1 p}, \mathbf{1 c}}$. 


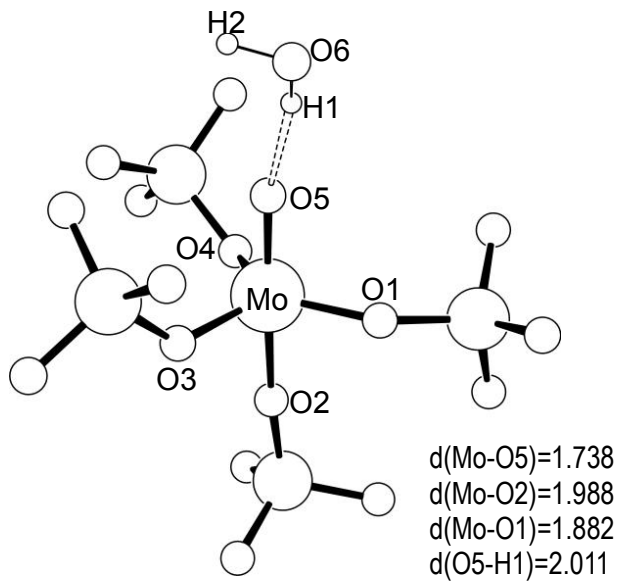

Mo6W

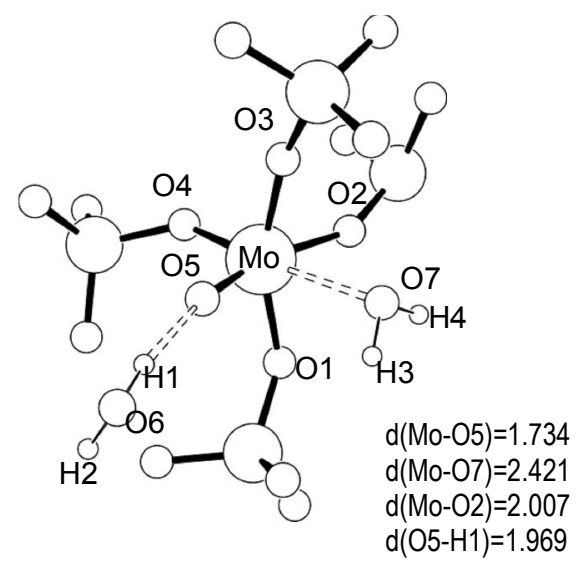

Mo6-2W $W^{1 p, 1 c}$

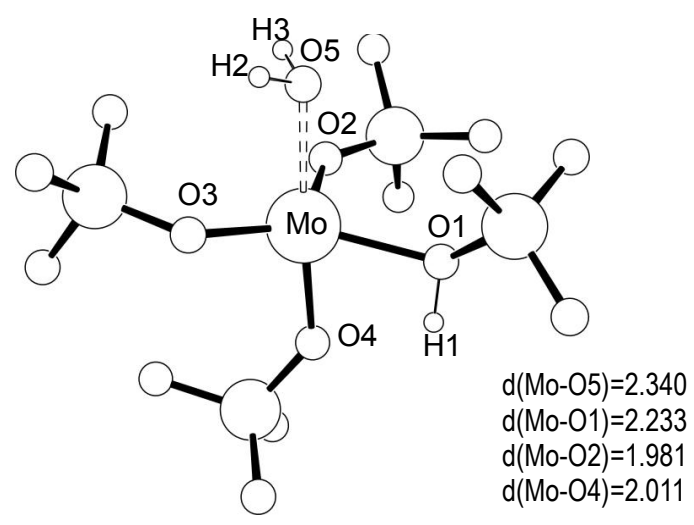

B3W

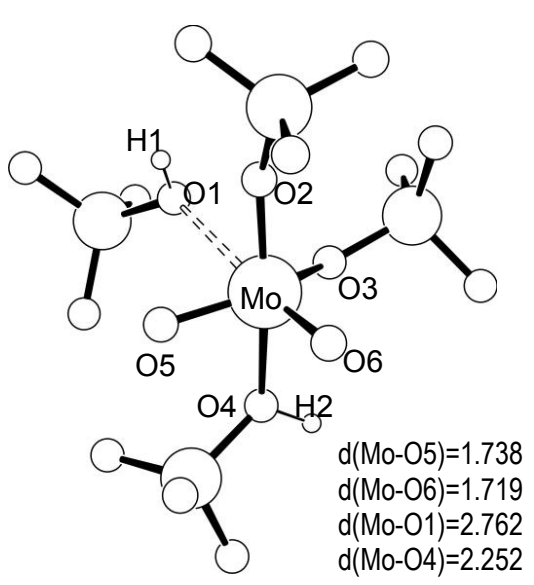

MoMo6

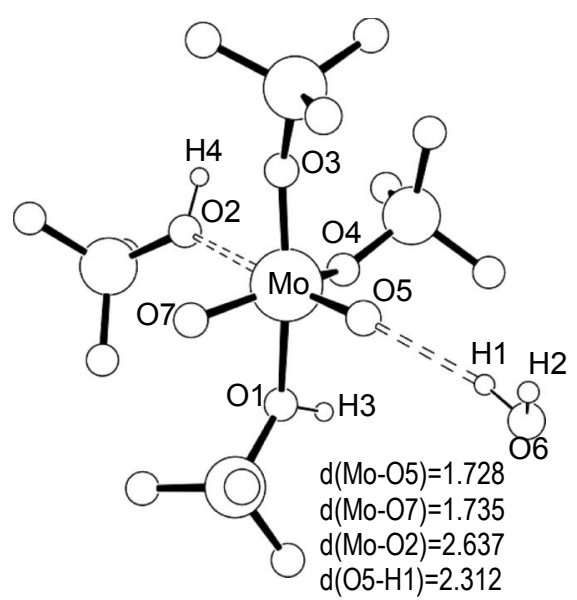

MoMo6W

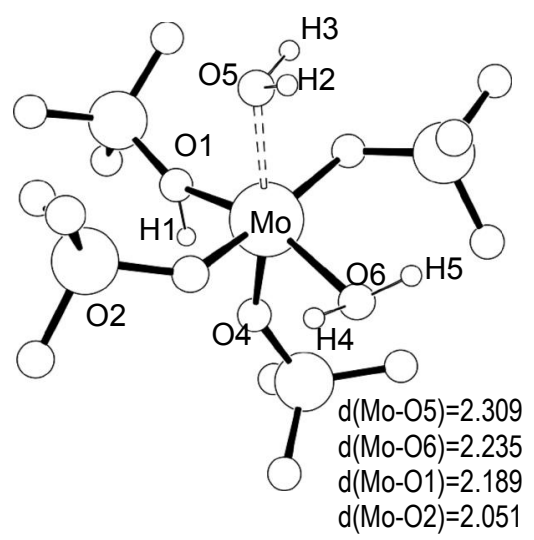

B3-2W

Figure 7. Adopted geometries and relevant structural metrics for the most important $\mathrm{Mo}^{\mathrm{VI}}$ and Mo ${ }^{\mathrm{III}}$ sites. 
Compared to $\mathrm{Mo}^{\mathrm{VI}}$ systems, water molecules entering the zeolite cage behave differently when approaching a $\mathrm{Mo}^{\mathrm{III}}$ substituted site. Due to the ease with which the zeolite framework distorts around the metal, the excess water coordinates to the $\mathrm{Mo}^{\mathrm{III}}$ center with one of its lone pairs to adopt a pentacoordinated, trigonal bipyramidal structure, B3W (Figure 2 and 7). The latter structure is the most stable one at this hydration state, however it is worth noting that splitting of water to $\mathrm{OH}^{-}$ and $\mathrm{H}^{+}$(TB3) is again a feasible process $(0.21 \mathrm{eV})$. Similarly to the first step, in the next hydration the water molecule prefers to build in into the coordination sphere of the metal as a ligand (B32W) to form an octahedral arrangement with two $\mathrm{H}_{2} \mathrm{O}$ ligands cis to each other. Mo-O distances of $2.05 \AA$ indicate a typical dative bond and relatively strong interaction between the metal and the chemisorbed water molecules.

Until the latter behavior of $\mathrm{Mo}^{\mathrm{III}}$ with water is very similar to that of $\mathrm{Cr}^{\mathrm{III}}$ substituted zeolite sites $^{6}$, the reactivity difference between $\mathrm{Cr}^{\mathrm{VI}}$ and $\mathrm{Mo}^{\mathrm{VI}}$ is remarkable. In contrast to the physisorbed most stable state for Mo6W, chromium(VI) tends to prefer hard $\mathrm{Cr}^{\cdots} \mathrm{O}$ interactions and, thus, it splits water to develop two $\mathrm{Cr}=\mathrm{O}$ interactions. Accordingly, the $\left[(\mathrm{SiO})_{2} \mathrm{CrO}_{2}\right]$ chromyl functionality is about $0.9 \mathrm{eV}$ more stable than the physisorbed state.

It is also worth discussing the overall geometries around the metal centers in the most stable structures (Figure 7), because the zeolite frame causes some deviations from the ideal structures in spite of its flexibility. Until the coordination sphere can adopt an almost perfect trigonal bipyramidal structure in Mo6W with very short $\mathrm{Mo}=\mathrm{O}$ bond in axial position $(\mathrm{d}=1.738 \AA)$, the structure of Mo6-2W deviates slightly from the ideal octahedral structure mostly due to the weak donor ability of the coordinated water molecule $(\mathrm{d}(\mathrm{Mo}-\mathrm{O} 7)=2.421 \AA)$, which allows the shift of the "ligands" towards this position. Similar distortions occur in MoMo6 and MoMo6W, in which the Si-OH group trans to the very strong oxo group elongates to $2.76 \AA$ and $2.60 \AA$, respectively, 
resulting in the bending of the equatorial plane. As mentioned above, with the entering of the water molecules to the coordination sphere of $\mathrm{Mo}^{\mathrm{III}}$, the structure is changing from tetrahedral to trigonalbipyramidal (tbp) and to octahedral as going from $\mathbf{B 3}$ to $\mathbf{B 3 W}$ and to $\mathbf{B 3 - 2 W}$ (Figure 7), respectively. The structure of $\mathbf{B 3 W}$, however, is not a perfect tbp, one of the angles between $\mathrm{Si}-$ $\mathrm{OH}$ and $\mathrm{Si}-\mathrm{O}-$ ligands in the equatorial plane distorts to $160^{\circ}$, from the ideal $120^{\circ}$. This metrical change actually opens a 'position' at the metal exactly in the direction of the sodalite cage, and this is where the next water molecule coordinates to form a slightly distorted octahedral structure (Figure 7).

Table 3. $\mathrm{OH}$ and $\mathrm{Mo}=\mathrm{O}$ vibrational frequencies in $\mathrm{cm}^{-1}$, calculated for different Mo model sites.

\begin{tabular}{llll}
\hline Vibration & Frequency & Vibration & Frequency \\
\hline SiO-H & 3811 & MoO-H & \\
B3 (SiO-H) & 3814 & MoTT6 & 3773 \\
TB3(SiO-H) & & MoTT6 & 3787 \\
& & TT6 & 3772 \\
SiO(H)Mo & 3754 & TT6 & 3816 \\
MoMo6 & 3808 & MoTB6 & 3742 \\
MoMo6 & 3761 & TBB3 & 3740 \\
MoTT6 & 3770 & TTB3 & 3752 \\
MoTB6 & 3811 & TTB3 & 3793 \\
B3 & 3678 & TB3 & 3700 \\
TBB3 & 3765 & & 1036 \\
TTB3 & 3777 & MoTT6 & 1032 \\
TTB3 & 3769 & Mo6 & \\
TB3 & 3540 & MoMo6 & 1070 \\
B32W & & MoMo6 & 1036 \\
& & Mo & \\
& & & \\
& & &
\end{tabular}




$\begin{array}{ll}\text { MoTB6 } & 1038 \\ \text { Mo6W } & 1033 \\ \text { MoMo6W } & 1033\end{array}$

Vibrational frequency calculations were carried out to verify that the structures reached a real minimum with only real frequencies and also to obtain spectroscopic properties. The computed frequencies (Table 3) are compared with experimental data for Mo loaded BEA using FTIR in situ measurement.

The calculations predict that the bridging $\mathrm{Mo}-\mathrm{O}(\mathrm{H})-\mathrm{Si}$ groups vibrate between $(3540-3777$ $\mathrm{cm}^{-1}$ ), terminal molybdenum-hydroxyl between $3700-3816 \mathrm{~cm}^{-1}$, while molybdenyl groups around $1030 \mathrm{~cm}^{-1}$ (probably visible with RAMAN) and silanol groups up to $3814 \mathrm{~cm}^{-1}$. From the experimental spectra showing a band around $3605 \mathrm{~cm}^{-1}$ a bridging hydroxyl $\mathrm{Si}-\mathrm{O}(\mathrm{H})-\mathrm{Mo}$ is expected.

\section{Acid-base properties}

To characterize the Brønsted acidity of the investigated structures, the protonation and deprotonation energy were calculated for the different energetically plausible $\operatorname{sites}^{54,55}$. The deprotonation energy is evaluated to be a positive value as the energy of the conjugate base, $\mathrm{E}\left(\mathrm{SOD}^{-}\right)$minus the energy of the acid (eq. 2). $\Delta \mathrm{E}_{\text {deprot }}$ indicates how acidic the proton is at a given site of the zeolite; the larger the $\Delta \mathrm{E}_{\text {deprot }}$ value the less acidic the proton is.

$$
\Delta \mathrm{E}_{\text {deprot }}=\mathrm{E}\left(\mathrm{SOD}^{-}\right)-\mathrm{E}(\mathrm{SOD}-\mathrm{H})
$$

The protonation energy is defined analogously in eq. 3 to measure the basicity of sites; however note that in this case a higher value of $\Delta \mathrm{E}_{\text {prot }}$ defines a more basic zeolite site.

$$
\Delta \mathrm{E}_{\text {prot }}=\mathrm{E}(\mathrm{SOD})-\mathrm{E}\left(\mathrm{SOD}-\mathrm{H}^{+}\right)
$$


One has to realize that a periodically repeated charged unit cell is modeled when computing energies $\mathrm{E}\left(\mathrm{SOD}^{-}\right)$and $\mathrm{E}\left(\mathrm{SOD}-\mathrm{H}^{+}\right)$resulting in an unphysical state of infinite overall charge for the macroscopic systems. The deprotonation and protonation energies should, thus, be corrected accordingly in order to obtain realistic absolute values. For example, the divergence of the Coulomb energy in the charged system is eliminated by adding a uniform positive/negative background charge to the deprotonated/protonated unit cell. Nevertheless, our experience is that the values computed via eq. 2 and 3 using this method reveal the correct acidity and basicity trends for the various sites, which is the primary aim of these simulations.

In practice, one can determine the acidity of the distinct silanol $(\mathrm{SiO}-\mathrm{H})$ groups, bridging hydroxyl $(\mathrm{SiO}(\mathrm{H})-\mathrm{Mo})$ groups and metal coordinated hydroxide $(\mathrm{MoO}-\mathrm{H})$ groups in the various oxidation and hydration states. Similarly, one can add a proton $\left(\mathrm{H}^{+}\right)$to the terminal molybdenumoxo group $(\mathrm{Mo}=\mathrm{O})$ or protonate the bridging oxygen $(\mathrm{Mo}-\mathrm{O}-\mathrm{Si})$ forming $\mathrm{Mo}=\mathrm{OH}^{+}$and $\mathrm{Mo}-$ $\mathrm{O}\left(\mathrm{H}^{+}\right)-\mathrm{Si}$ functionalities, respectively. The computed protonation and deprotonation energies are tabulated in Table 4 for the most relevant structures in electron volts.

Table 4. Deprotonation and protonation energies calculated for the $\mathrm{Mo}^{\mathrm{VI}}$ model sites for Mo6 and MoMo6. (Values in eV)

\begin{tabular}{lrlc}
\hline & $\Delta \mathrm{E}_{\text {deprot }}$ & & \multicolumn{1}{c}{$\Delta \mathrm{E}_{\text {prot }}$} \\
\hline MoMo6(SiO-H) & 4.57 & Mo6 & 4.03 \\
MoMo6(SiO(H)-Mo) & 5.23 & MoMo6 & 4.56 \\
& & MoMo6 & 3.98
\end{tabular}

Bridging oxygen

Mo6

MoMo6 $\quad 4.62$ 
Two conclusions can be drawn from the computed deprotonation energies in general; the values span a range of $1.75 \mathrm{eV}$ indicating that the acidity can vary drastically in the zeolite amongst sites and there is no unambiguous tendency in the acid strengths of $\mathrm{Mo}-\mathrm{OH}, \mathrm{SiO}(\mathrm{H})-\mathrm{Mo}$ and $\mathrm{SiO}-$ $\mathrm{H}$ sites. The latter finding might sound discouraging at first, however it clearly emphasis the importance of H-bond networks and auxiliary electrostatic interactions in the zeolite frame. By allowing the relaxation of the deprotonated structure we can witness the reorganization of these hydrogen-networks, which has a non-systematic contribution to the stabilization in the structures with different arrangement around the metal, oxidation state and hydration state. Still, if one looks only at the distribution, one finds more $\mathrm{Mo}^{\mathrm{III}}$ sites in the very acidic as well as in the most basic regimes indicating high affinity to react and, accordingly, one should expect the absence of these sites in the zeolite, as it is indeed the case for molybdenum.

Concerning the most relevant $\mathrm{Mo}^{\mathrm{VI}}$ sites, the $\mathrm{Si}-\mathrm{OH}$ functionalty appears to be more acidic than the $\mathrm{SiO}(\mathrm{H})-\mathrm{Mo}$ functionality in MoMo6. Finally, side-by-side comparison of the $\Delta \mathrm{E}_{\text {deprot }}$ values for $\mathrm{Cr}$ and Mo substituted analogues reveals more acidic Mo-based sites (by about $0.3-0.5 \mathrm{eV}$ ) as a result of the larger effective charge, which stabilizes the negative charge generated upon dehydrogenation.

$\Delta \mathrm{E}_{\text {prot }}$ varies in a wide range of about $2.7 \mathrm{eV}$ indicating very different basicity for some sites, however the $\mathrm{Mo}^{\mathrm{VI}}$ sites appear exclusively in the low basicity regime $\left(\Delta \mathrm{E}_{\text {prot }}=\sim 4 \mathrm{eV}\right)$. Bridging oxygens act slightly basic than terminal hydroxyls and molybdenyl groups. Comparing to $\mathrm{Cr}$ substituted zeolites we see a systematic negative shift $(-0.5--1.5 \mathrm{eV})$ in the bridging oxygen $(\mathrm{M}-$ $\mathrm{O}-\mathrm{Si}$ ) basicity showing that these bridging oxygens become less basic when $\mathrm{Cr}$ is replaced to Mo.

\section{BEA Results}


We have repeatedly demonstrated in integrated experimental and computational studies that the simple sodalite (SOD) model provides a sufficiently realistic structural description for the metal containing site of the zeolite. Nevertheless, in cases when structurally significantly differing but energetically similar sites are present, e.g. Mo6W vs. MoMo6, the sodalite framework might be too rigid to account for subtle differences in the stability-structure relationship. To get a more realistic insight into the structures and energetics of the most stable forms, we remodeled the Mo6, Mo6W, MoMo6, Mo6-2W'1c,1p, Mo6-2W ${ }^{2 p}$ and MoMo6W sites in BEA zeolite. Due to the size of the BEA unit cell (192 atoms), and the number of different T sites (9), a complete BEA study would have been computationally very resource demanding. For this reason, our investigation is limited to three T-sites, T1, T2, and T9, which were selected on the bases of our previous work ${ }^{11}$, showing that these $\mathrm{T}$-sites exhibit very different affinity to accommodate $\mathrm{M}=\mathrm{O}, \mathrm{M}-\mathrm{OH}$ groups, respectively.

Table 5. Relative stabilities of the most stable structures at T1, T2 and T9 sites in BEA zeolite in $\mathrm{eV}$.

\begin{tabular}{llll}
\hline & T1 & T2 & T9 \\
\hline Mo & 0.09 & 0.03 & 0.00 \\
\hline Mo6 & 0.18 & 0.10 & 0.00 \\
\hline Mo6W & 0.19 & 0.12 & 0.00 \\
MoMo6 & 0.08 & 0.08 & 0.89 \\
\hline Mo6-2W $2 \mathrm{p}$ & 2.08 & 0.23 & n.a. \\
Mo6-2W & 0.53 & 2.34 & n.a. \\
MoMo6W & 0.00 & 0.35 & 1.02 \\
\hline
\end{tabular}


Table 5 shows how the relative stabilities of the selected structures depend on three $\mathrm{T}$ sites of the BEA zeolite. There are only subtle differences $(0.089$ and $0.034 \mathrm{eV})$ between $\mathrm{T}$ sites for the isoelectronic substitution of a silicon atom to a $\mathrm{Mo}^{\mathrm{IV}}$. More pronounced differences can be seen for the $\mathrm{Mo}^{\mathrm{VI}}$ state $(\mathrm{Mo6})$; the $(-\mathrm{SiO}) 4 \mathrm{Mo}=\mathrm{O}$ functionality is 0.100 and $0.179 \mathrm{eV}$ more stable at the $\mathrm{T} 9$ position than in $\mathrm{T} 2$ and $\mathrm{T} 1$, respectively. As expected, the same pattern in $\mathrm{T}$ sites with similar magnitudes appears for the Mo6W, which has the same electronic structure around the molybdenum as in Mo6 but with an extra physisorbed water molecule. For Mo6-2 $\mathbf{W}^{\mathbf{2 p}}$ with two physisorbed water molecules, one would expect the same behavior, however, spatial requirements and hydrogen networks completely hinder this original trend amongst $\mathrm{T}$ sites, resulting in a most stable T2 site.

Very different behavior is revealed for the MoMo6 and MoMo6W forms. Then again, in these structures the water molecule is split into an ' $\mathrm{O}^{2-}$, and two ' $\mathrm{H}^{+}$'s to form a new $\mathrm{Mo}=\mathrm{O}$ bond and two H-OSi functionalities. Significant structural distortions of the zeolite framework are accompanied with this process and our simulations clearly demonstrated that the different $\mathrm{T}$ sites adopt these structural changes very differently. Namely, T1 and T2 sites profit more from this structural relaxation/distortion than T9 site and accordingly the water splitting process, i.e. going from Mo6W to MoMo6, becomes preferred at T1 and T2 sites by 0.1 and $0.04 \mathrm{eV}$, respectively. The appealing consistency of our calculations is clearly reflected in the stability order of MoMo6W amongst the T sites being similar to that of MoMo6, as expected on the electronic structure similarity; T1 site is the most stable whereas T9 is the least stable when hosting Mo ${ }^{\mathrm{VI}}$ with two $\mathrm{Mo}=\mathrm{O}$ functionalities. At this hydration state water spitting is strongly preferred at $\mathrm{T} 1$ ($0.53 \mathrm{eV})$, it is an equilibrium process at $\mathrm{T} 2(0.12 \mathrm{eV})$, whereas most probably is an uphill process at T9. Thus, our calculations unambiguously revealed different structural relaxation or distortion 
ability at different $\mathrm{T}$ sites which is manifested in the reactivity of the molybdenum center at these positions.

It is also worth noting that in cases when the reactive site undergoes so drastic structural change upon a reaction as in the case of going from Mo6W to MoMo6, i.e. water splitting, the sodalite cage might not provide a realistic picture about the energetics due to its inability to distort its frame properly. For example, simulations in SOD predict a thermodynamically not preferred water spitting for the Mo6W to MoMo6 transition, whereas it is clearly a feasible process at the T1 position in the BEA frame. In these instances, modeling the processes in BEA zeolite is crucial after prescreening the various structures with the simple SOD model. Similar conclusion can be drawn for the computed equilibrium geometries: simulations in SOD and BEA reveal conceptually similar arrangements around the molybdenum center, however, fluctuations in the structural metrics, up to $0.2 \AA$ for weak bonds, might be expected when going from one zeolite frame to another.

\section{Conclusions}

We effectively prepared Mo-containing BEA zeolites by using a two-steps post-synthesis method starting from SiBEA and $\mathrm{Mo}^{\mathrm{II}}$ acetate. The incorporation of molybdenum ions into the zeolite framework was evidenced and characterized by several experimental techniques; most importantly X-ray diffractograms indicate a characteristic framework expansion upon Mo loading, whereas FTIR measurements strongly support that the isolated Mo containing sites have been formed upon reaction of Mo ions with silanol groups of vacant T-atom sites. Moreover, DR-UVvis measurements provide unambiguous evidence for LMCT charge transfer for $\mathrm{O}^{2-}$ to $\mathrm{Mo}^{\mathrm{VI}}$ transitions; the peaks at 265 and $310 \mathrm{~nm}$ resemble to documented $\mathrm{O} \rightarrow \mathrm{Mo}^{\mathrm{VI}}$ transitions in tetrahedral and octahedral environments, respectively, however other geometries, e.g. five 
coordinated trigonal-bypiramidal or square-pyramidal structures also cannot be definitely excluded due to the overlap of the characteristic peaks of $\mathrm{O}^{2-} \rightarrow \mathrm{Mo}^{\mathrm{VI}}$ in these arrangements. The formation of Brønsted and Lewis acidic sites, i.e. $-\mathrm{OH}$ and $\mathrm{Mo}^{\mathrm{VI}}$ functionalities, in $\mathrm{Mo}_{3.0}$ SiBEA were further evidenced by FTIR investigations; using pyridine as adsorption probe molecule, the appearance of pyridinum ion and $\mathrm{Mo}^{\mathrm{VI}}$ coordinated pyridine was observed.

Systematic periodic plane-wave simulations using a model sodalite cage have been carried out to get insight into the relative stability and structure of plausible isomeric molybdenum sites in +6 and +3 oxidation states and different hydration states. The low protonation and deprotonation values as well as the ease with which $\mathrm{Mo}^{\mathrm{III}}$ centers bind water molecules indicate that $\mathrm{Mo}^{\mathrm{III}}$ loaded sites are very reactive and most probably undergo oxidation to $\mathrm{Mo}^{\mathrm{VI}}$ with suitable reactants, e.g. under $\mathrm{O}_{2}$, in line with the lack of d-d transitions in the DR UV-vis spectra indicating only $\mathrm{Mo}^{\mathrm{VI}}$ cores. The most plausible $\mathrm{Mo}^{\mathrm{VI}}$ site under anhydrous conditions has a trigonal-bipyramidal structure with four $\mathrm{Mo}-\mathrm{OSi}-$ bonds integrated into the zeolite frame and with a molybdenyl $(\mathrm{Mo}=\mathrm{O})$ functionality in an axial position (Mo6). Upon hydration, we see the coordination of the entering water molecule to this $\mathrm{Mo}=\mathrm{O}$ functionality via an $\mathrm{O} \cdots \mathrm{H}$ hydrogen bond (Mo6W). The second water molecule rather coordinates to the molybdenum center with its oxygen to form a pseudo-octahedral species (Mo6-2W $\left.\mathbf{W}^{\mathbf{1} \mathbf{p}, \mathbf{1 c}}\right)$. Water splitting might be feasible in the former case at higher temperatures, whereas this process is energetically favorable $(-0.031 \mathrm{eV})$ in the latter hydration state according to the calculations in the SOD model cage. The reaction with water results in two $\mathrm{Mo}=\mathrm{O}$ functionalities at the metal and $\mathrm{SiOH}$ termini for the zeolite frame.

Remodeling the most stable $\mathrm{Mo}^{\mathrm{VI}}$ sites in three $\mathrm{T}$ positions (T1, T2 and T9) of BEA framework, using a unit cell of 192 atoms periodically, indicates that reactivity of molybdenum based sites is significantly influenced by the rigidity/flexibility of the zeolite frame to adopt a certain structure 
characteristic the product. A slight preference for the penta-coordinated $(\mathrm{SiO}-)_{4} \mathrm{Mo}=\mathrm{O}$ species is revealed at the $\mathrm{T} 9$ position over $\mathrm{T} 1$ and $\mathrm{T} 2 . \mathrm{T} 1$ is, however, superior in adopting pseudo-octahedral $(\mathrm{SiO}-)_{2}(\mathrm{Si}(\mathrm{H}) \mathrm{O}-)_{2} \mathrm{Mo}(=\mathrm{O})_{2}$ structures resulting in significantly favoured water splitting processes. The latter process is also feasible at molybdenum in $\mathrm{T} 2$ position, but it is an energetically uphill process for Mo sites at T9 due to the rigidity of the zeolite frame in this position. From these results it is also clear that the sodalite model cage might serve to pre-estimate the stability of the numerous plausible isomers, however, more realistic zeolite models, such as BEA, is needed to adequately assess the stability-structure relationship for close energy states, such as for water splitting reaction in this study.

\section{Acknowledgement}

This work was performed using HPC resources from GENCI- [CCRT/CINES/IDRIS] (Grant 2015-[x2015082022]) and the CCRE of Université Pierre et Marie Curie. G.S., F.D.P and F.T wish to acknowledge the French-Belgian bilateral PHC Tournesol Project $\mathrm{N}^{\circ} 25264 \mathrm{TA}$ for financial support.

\section{Corresponding Author}

F. Tielens, e-mail: frederik.tielens@upmc.fr, tel.: +33 1 44276004, fax: +33 144271507

\section{Author Contributions}

The manuscript was written through contributions of all authors. All authors have given approval to the final version of the manuscript. 


\section{REFERENCES}

1. Sachtler, W.M.H., Zeolite-Supported Transition Metal Catalysts by Design. Catalysis Today, 1992, 15, 419-429.

2. Derouane, E.G.; Védrine, J.C.; Pinto, R.R.; Borges, P.M.; Costa, L.; Lemos, M.A.N.D.A.; Lemos, F.; and Ribeiro, F.R., The Acidity of Zeolites: Concepts, Measurements and Relation to Catalysis: A Review on Experimental and Theoretical Methods for the Study of Zeolite Acidity. Catalysis Reviews, 2013, 55, 454-515.

3. Dzwigaj, S. and Shishido, T., State of Chromium in Crsibea Zeolite Prepared by the Two-Step Postsynthesis Method: XRD, FTIR, UV-Vis, EPR, TPR, and XAS Studies. The Journal of Physical Chemistry C, 2008, 112, 5803-5809.

4. Janas, J.; Gurgul, J.; Socha, R.P.; Kowalska, J.; Nowinska, K.; Shishido, T.; Che, M.; and Dzwigaj, S., Influence of the Content and Environment of Chromium in Crsibea Zeolites on the Oxidative Dehydrogenation of Propane. The Journal of Physical Chemistry C, 2009, 113, 13273-13281.

5. Baran, R.; Ayerseng, F.; Millot, Y.; Onfroy, T.; Casale, S.; and Dzwigaj, S., Incorporation of Mo into the Vacant T-Atom Sites of the Framework of BEA Zeolite as Mononuclear Mo Evidenced by XRD and FTIR, NMR, EPR, and DR UV-Vis Spectroscopies. Journal of Physical Chemistry C, 2014, 118, 4143-4150.

6. Tielens, F.; Islam, M.M.; Skara, G.; De Proft, F.; Shishido, T.; and Dzwigaj, S., Chromium Sites in Zeolite Framework: Chromyl or Chromium Hydroxyl Groups. Microporous and Mesoporous Materials, 2012, 159, 66-73.

7. Lewandowska, A.E.; Banares, M.A.; Tielens, F.; Che, M.; and Dzwigaj, S., Different Kinds of Tetrahedral V Species in Vanadium-Containing Zeolites Evidenced by Diffuse 
Reflectance UV-Vis, Raman, and Periodic Density Functional Theory. The Journal of Physical Chemistry C, 2010, 114, 19771-19776.

8. Tielens, F.; Calatayud, M.; Dzwigaj, S.; and Che, M., What Do Vanadium Framework Sites Look Like in Redox Model Silicate Zeolites? Microporous and Mesoporous Materials, 2009, 119, 137-143.

9. Tielens, F. and Dzwigaj, S., Probing Acid-Base Sites in Vanadium Redox Zeolites by DFT Calculation and Compared with FTIR Results. Catalysis Today, 2010, 152, 66-69.

10. Tielens, F.; Trejda, M.; Ziolek, M.; and Dzwigaj, S., Nature of Vanadium Species in V Substituted Zeolites: A Combined Experimental and Theoretical Study. Catalysis Today, 2008, 139, 221-226.

11. Wojtaszek, A.; Ziolek, M.; Dzwigaj, S.; and Tielens, F., Comparison of Competition between $\mathrm{T}=\mathrm{O}$ and $\mathrm{T}-\mathrm{OH}$ Groups in Vanadium, Niobium, Tantalum BEA Zeolite and SOD Based Zeolites. Chemical Physics Letters, 2011, 514, 70-73.

12. Tielens, F.; Shishido, T.; and Dzwigaj, S., What Do the Niobium Framework Sites Look Like in Redox Zeolites? A Combined Theoretical and Experimental Investigation. The Journal of Physical Chemistry C, 2010, 114, 3140-3147.

13. Tielens, F.; Shishido, T.; and Dzwigaj, S., What Do Tantalum Framework Sites Look Like in Zeolites? A Combined Theoretical and Experimental Investigation. The Journal of Physical Chemistry C, 2010, 114, 9923-9930.

14. Guesmi, H.; Gryboś, R.; Handzlik, J.; and Tielens, F., Characterization of Molybdenum Monomeric Oxide Species Supported on Hydroxylated Silica; a DFT Study. Physical Chemistry Chemical Physics, 2014, 16, 18253-18260. 
15. Spencer, N.D.; Pereira, C.J.; and Grasselli, R.K., The Effect of Sodium on the $\mathrm{MoO}_{3}-$ $\mathrm{SiO}_{2}$-Catalyzed Partial Oxidation of Methane. Journal of Catalysis, 1990, 126, 546-554.

16. Banares, M.A.; Fierro, J.L.G.; and Moffat, J.B., The Partial Oxidation of Methane on $\mathrm{MoO}_{3} / \mathrm{SiO}_{2}$ Catalysts: Influence of the Molybdenum Content and Type of Oxidant. Journal of Catalysis, 1993, 142, 406-417.

17. Giordano, N.; Meazza, M.; Castellan, A.; Bart, J.C.J.; and Ragaini, V., Structure and Catalytic Activity of $\mathrm{MoO}_{3} \cdot \mathrm{SiO}_{2}$ Systems: III. Mechanism of Oxidation of Propylene. Journal of Catalysis, 1977, 50, 342-352.

18. Ono, T.; Anpo, M.; and Kubokawa, Y., Catalytic Activity and Structure of Molybdenum Trioxide Highly Dispersed on Silica. The Journal of Physical Chemistry, 1986, 90, 47804784.

19. Louis, C.; Tatibouët, J.-M.; and Che, M., Catalytic Properties of Silica-Supported Molybdenum Catalysts in Methanol Oxidation: The Influence of Molybdenum Dispersion. Journal of Catalysis, 1988, 109, 354-366.

20. Thangaraj, A.; Sivasanker, S.; and Ratnasamy, P., Catalytic Properties of Crystalline Titanium Silicalites III. Ammoximation of Cyclohexanone. Journal of Catalysis, 1991, 131, 394-400.

21. Reddy, J.S. and A., S.

22. Kraushaar-Czarnetzki, B. and Van Hooff, J.H.C., A Test Reaction for Titanium Silicalite Catalysts. Catal Lett, 1989, 2, 43-47.

23. Yamashita, H.; Yoshizawa, K.; Ariyuki, M.; Higashimoto, S.; Che, M.; and Anpo, M., Photocatalytic Reactions on Chromium Containing Mesoporous Silica Molecular Sieves 
(Cr-HMS) under Visible Light Irradiation: Decomposition of No and Partial Oxidation of Propane. Chemical Communications, 2001, 435-436.

24. Guesmi, H.; Grybos, R.; Handzlik, J.; and Tielens, F., Characterization of Molybdenum Monomeric Oxide Species Supported on Hydroxylated Silica: A DFT Study. Physical Chemistry Chemical Physics, 2014, 16, 18253-18260.

25. Dines, T.J. and Inglis, S., Raman Spectroscopic Study of Supported Chromium(VI) Oxide Catalysts. Physical Chemistry Chemical Physics, 2003, 5, 1320-1328.

26. Demmelmaier, C.A.; White, R.E.; van Bokhoven, J.A.; and Scott, S.L., Evidence for a Chromasiloxane Ring Size Effect in Phillips $\left(\mathrm{Cr} / \mathrm{SiO}_{2}\right)$ Polymerization Catalysts. Journal of Catalysis, 2009, 262, 44-56.

27. Miller, R.M.; Tinti, D.S.; and Case, D.A., Comparison of the Electronic Structures of Chromate, Halochromates, and Chromyl Halides by the X.Alpha. Method. Inorganic Chemistry, 1989, 28, 2738-2743.

28. Tielens, F., Exploring the Reactivity of Framework Vanadium, Niobium, and Tantalum Sites in Zeolitic Materials Using DFT Reactivity Descriptors. J. Comput. Chem., 2009, 30, 1946-1951.

29. Tielens, F., Exploring the Reactivity of Intraframework Vanadium, Niobium and Tantalum Sites in Zeolitic Materials Using the Molecular Electrostatic Potential. Journal of Molecular Structure: THEOCHEM, 2009, 903, 23-27.

30. Tielens, F. and Dzwigaj, S., Group V Metal Substitution in Silicate Model Zeolites: In Search for the Active Site. Chemical Physics Letters, 2010, 501, 59-63. 
31. Kresse, G. and Furthmuller, J., Efficiency of Ab-Initio Total Energy Calculations for Metals and Semiconductors Using a Plane-Wave Basis Set. Comput. Mater. Sci., 1996, 6, $15-50$.

32. Kresse, G. and Hafner, J., Ab Initio Molecular-Dynamics Simulation of the LiquidMetal-Amorphous-Semiconductor Transition in Germanium. Physical Review B, 1994, 49, 14251-14269.

33. Perdew, J.P.; Burke, K.; and Ernzerhof, M., Generalized Gradient Approximation Made Simple. Physical Review Letters, 1996, 77, 3865-3868.

34. Perdew, J.P.; Burke, K.; and Ernzerhof, M., Generalized Gradient Approximation Made Simple. Physical Review Letters , 1996, 77, 3865. Physical Review Letters, 1997, 78, 1396-1396.

35. Blochl, P.E., Projector Augmented-Wave Method. Physical Review B, 1994, 50, 1795317979.

36. Kresse, G. and Joubert, D., From Ultrasoft Pseudopotentials to the Projector AugmentedWave Method. Physical Review B, 1999, 59, 1758-1775.

37. Blöchl, P.; Jepsen, O.; and Andersen, O., Improved Tetrahedron Method for BrillouinZone Integrations. Physical Review B, 1994, 49, 16223-16233.

38. Dzwigaj, S.; Matsuoka, M.; Franck, R.; Anpo, M.; and Che, M., Probing Different Kinds of Vanadium Species in the VSi $\beta$ Zeolite by Diffuse Reflectance UV-Visible and Photoluminescence Spectroscopies. The Journal of Physical Chemistry B, 1998, 102, $6309-6312$

39. Kumar Rana, R. and Viswanathan, B., Mo Incorporation in MCM-41 Type Zeolite. Catal Lett, 1998, 52, 25-29. 
40. So, H. and Pope, M.T., Origin of Some Charge-Transfer Spectra. Oxo Compounds of Vanadium, Molybdenum, Tungsten, and Niobium Including Heteropoly Anions and Heteropoly Blues. Inorganic Chemistry, 1972, 11, 1441-1443.

41. Dzwigaj, S.; J. Peltre, M.; Massiani, P.; Davidson, A.; Che, M.; Dzwigaj, S.; Massiani, P.; Sen, T.; and Sivasanker, S., Incorporation of Vanadium Species in a Dealuminated Small Beta Zeolite. Chemical Communications, 1998, 87-88.

42. Dzwigaj, S.; Massiani, P.; Davidson, A.; and Che, M., Role of Silanol Groups in the Incorporation of V in B Zeolite. Journal of Molecular Catalysis A: Chemical, 2000, 155, $169-182$

43. Dzwigaj, S.; Matsuoka, M.; Anpo, M.; and Che, M., Evidence of Three Kinds of Tetrahedral Vanadium (V) Species in VSi $\beta$ Zeolite by Diffuse Reflectance UV-Visible and Photoluminescence Spectroscopies. The Journal of Physical Chemistry B, 2000, 104, $6012-6020$.

44. Centi, G.; Perathoner, S.; Trifiro, F.; Aboukais, A.; Aissi, C.F.; and Guelton, M., Physicochemical Characterization of V-Silicalite. The Journal of Physical Chemistry, 1992, 96, 2617-2629.

45. Thielemann, J.P.; Ressler, T.; Walter, A.; Tzolova-Müller, G.; and Hess, C., Structure of Molybdenum Oxide Supported on Silica SBA-15 Studied by Raman, UV-Vis and X-Ray Absorption Spectroscopy. Applied Catalysis A: General, 2011, 399, 28-34.

46. Fournier, M.; Louis, C.; Che, M.; Chaquin, P.; and Masure, D., Polyoxometallates as Models for Oxide Catalysts: Part I. An UV-Visible Reflectance Study of Polyoxomolybdates: Influence of Polyhedra Arrangement on the Electronic Transitions 
and Comparison with Supported Molybdenum Catalysts. Journal of Catalysis, 1989, 119, $400-414$

47. Zecchina, A.; Bordiga, S.; Spoto, G.; Marchese, L.; Petrini, G.; Leofanti, G.; and Padovan, M., Silicalite Characterization. 2. IR Spectroscopy of the Interaction of Carbon Monoxide with Internal and External Hydroxyl Groups. The Journal of Physical Chemistry, 1992, 96, 4991-4997.

48. Góra-Marek, K.; Datka, J.; Dzwigaj, S.; and Che, M., Influence of V Content on the Nature and Strength of Acidic Sites in VSi $\beta$ Zeolite Evidenced by IR Spectroscopy. The Journal of Physical Chemistry B, 2006, 110, 6763-6767.

49. Busca, G.; Centi, G.; Trifiro, F.; and Lorenzelli, V., Surface Acidity of Vanadyl Pyrophosphate, Active Phase in N-Butane Selective Oxidation. The Journal of Physical Chemistry, 1986, 90, 1337-1344.

50. Centi, G.; Golinelli, G.; and Busca, G., Modification of the Surface Pathways in Alkane Oxidation by Selective Doping of Bronsted Acid Sites of Vanadyl Pyrophosphate. The Journal of Physical Chemistry, 1990, 94, 6813-6819.

51. Knöuzinger, H., Specific Poisoning and Characterization of Catalytically Active Oxide Surfaces, in Advances in Catalysis, D.D. Eley, H.P. and Paul, B.W., Editors. 1976, Academic Press. p. 184-271.

52. Hardcastle, F.D. and Wachs, I.E., Determination of Molybdenum-Oxygen Bond Distances and Bond Orders by Raman Spectroscopy. Journal of Raman Spectroscopy, $1990,21,683-691$

53. Bolis, V.; Busco, C.; and Ugliengo, P., Thermodynamic Study of Water Adsorption in High-Silica Zeolites. The Journal of Physical Chemistry B, 2006, 110, 14849-14859. 
54. Calatayud, M.; Tielens, F.; and De Proft, F., Reactivity of Gas-Phase, Crystal and Supported $\mathrm{V}_{2} \mathrm{O}_{5}$ Systems Studied Using Density Functional Theory Based Reactivity Indices. Chemical Physics Letters, 2008, 456, 59-63.

55. Eichler, U.; Brändle, M.; and Sauer, J., Predicting Absolute and Site Specific Acidities for Zeolite Catalysts by a Combined Quantum Mechanics/Interatomic Potential Function Approach. The Journal of Physical Chemistry B, 1997, 101, 10035-10050. 
Table of Contents Graphic

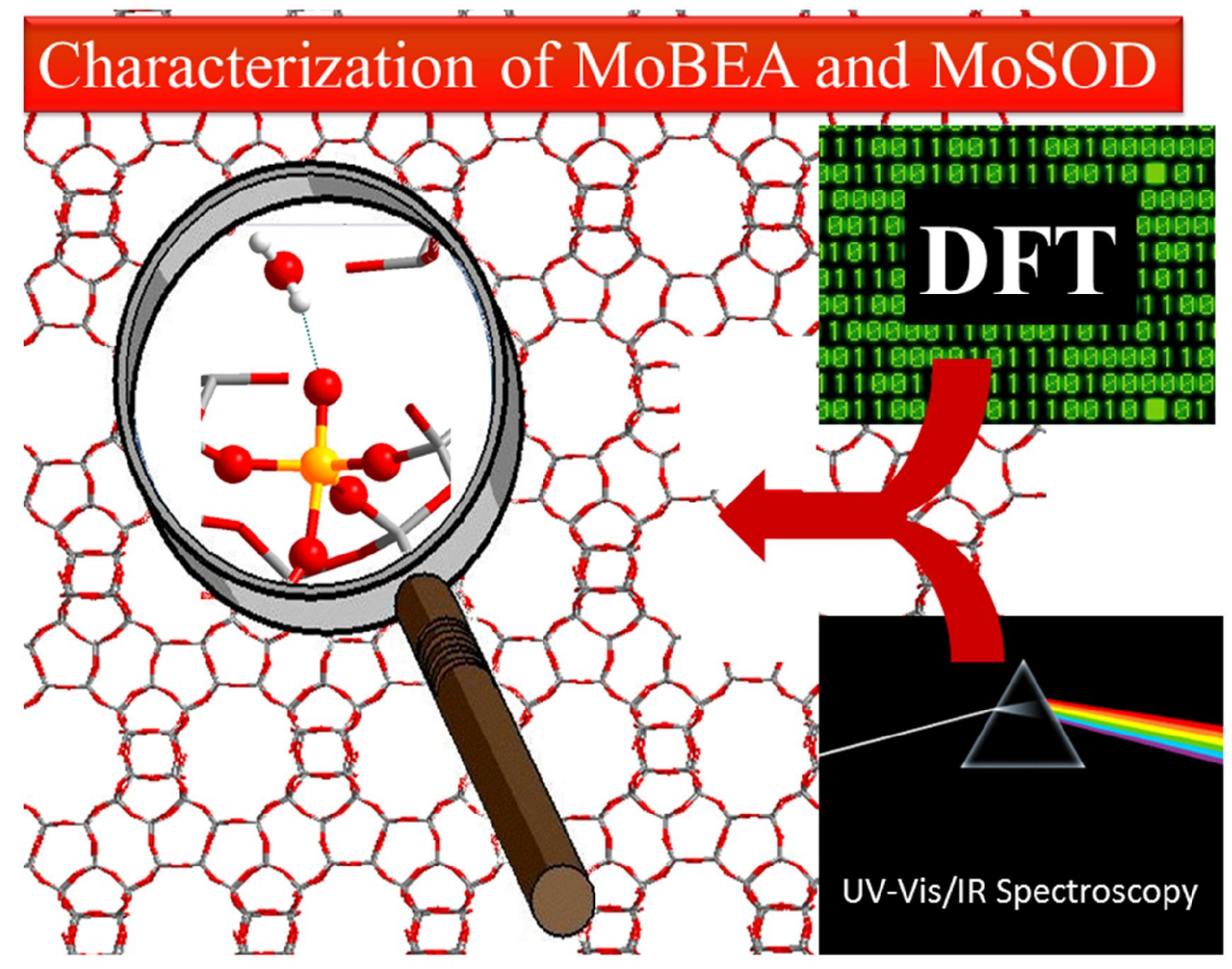

